\title{
A DISCRETE PARTICLE SIMULATION STUDY ON THE INFLUENCE OF RESTITUTION COEFFICIENT ON SPOUT FLUIDIZED BED DYNAMICS
}

\author{
M.S. van Buijtenen ${ }^{1}$, N.G. Deen ${ }^{1}$, S. Antonyuk ${ }^{2}$, S. Heinrich ${ }^{2}$ and J.A.M. Kuipers $^{1}$ \\ ${ }^{1}$ University of Twente, Faculty of Science and Technology, The Netherlands \\ ${ }^{2}$ Otto-von-Guericke-University Magdeburg, Faculty of Process and Systems Engineering, Germany
}

\begin{abstract}
In this paper the influence of the normal restitution coefficient on the bed dynamics during different flow regimes was studied using the discrete element model. The three flow regimes comprise the intermediate/spout-fluidization, spouting-with-aeration regime and the jetin-fluidized-bed. It is shown that with increase of the restitution coefficient the average bed height decreases for all flow regime cases. To study the influence of the granule impact velocity and the liquid film on the wall surface the free-fall experiments in the velocity range of 0.5 $4.5 \mathrm{~m} / \mathrm{s}$ were performed with spherical $\gamma-\mathrm{Al}_{2} \mathrm{O}_{3}$ granules. During the free-fall tests, the impact angle from $0^{\circ}$ to $80^{\circ}$ and the viscosity of thin liquid film in the range of $1-300 \mathrm{mPa} \cdot \mathrm{s}$ were varied.
\end{abstract}

\section{INTRODUCTION}

Spout fluidized beds are frequently used for the production of granules through granulation, which are widely applied for example in the production of detergents, pharmaceuticals, food and fertilizers (Mörl et al. (2007)). During the granulation process, particles contain different loadings of moisture which results in varying collision properties in time and location across the bed. The moisture content in spout fluidized beds has a great influence on the inter-particle collision properties and hence on the flow behaviour, Passos and Mujumdar (2000), Vieira and Rocha (2004). The wet granules exhibit elastic-plastic or dominant plastic behaviour during the collision. Their kinetic impact energy dissipates due to plastic deformation, adhesion, friction in the contact of the granule with other granule or the apparatus wall. The restitution coefficient is a very important material parameter, which is needed to consider this energy loss in numerical discrete modelling of particle and particle-fluid flows, Kruggel-Emden (2006). The restitution coefficient is the square root of the ratio of elastic energy $\mathrm{W}_{\mathrm{kin}, \mathrm{R}}$ released during the restitution to the initial kinetic impact energy $\mathrm{W}_{\text {kin }}$ :

$$
e=\sqrt{\frac{W_{k i n, R}}{W_{k i n}}}=\sqrt{1-\frac{W_{d i s s}}{W_{k i n}}}=\frac{\mathrm{v}_{R}}{\mathrm{v}} \approx \sqrt{\frac{h_{R}}{h}} .
$$

For an elastic-plastic impact, the restitution coefficient is in the range of $0<\mathrm{e}<1$, see examples in Walton and Braun (1986), Kharaz et al. (2001), Fu et al. (2004), Antonyuk (2006). The normal and oblique impacts are described by normal and tangential coefficients of restitution:

$$
e_{n}=\mathrm{v}_{n, R} / \mathrm{v}_{n}, e_{t}=\mathrm{v}_{t, R} / \mathrm{v}_{t}
$$

where $\mathrm{v}_{\mathrm{n}}$ and $\mathrm{v}_{\mathrm{t}}$ are normal and tangential components of the velocity vector, respectively.

In this work we use fundamental, deterministic models to enable the detailed investigation of granulation behaviour in a spout fluidized bed. A discrete element model (DEM) is used to describe the dynamics of the particles in gas-phase. The gas phase flow field is computed from the volume-averaged Navier-Stokes equations. The DEM is based on the hard-sphere contact model originally developed by Hoomans et al. (1996) and extended by Link et al. (2007) for the simulation of spout fluidized beds. One objective of this work is to gain insight in the effect of the restitution coefficient on the flow behaviour of spout fluidized beds at different flow regimes. In addition, the fall-tests with a model material $\left(\gamma-\mathrm{Al}_{2} \mathrm{O}_{3}\right.$ granules $)$ were performed to study the influences of the granule impact velocity and the liquid film viscosity on the restitution coefficient.

\section{TEST CASES}

The simulations have been conducted using different values of the normal restitution coefficient, ranging from 0.2 to 0.97 . In Table 1 the particle properties are listed, the studied flow regimes are shown in Table 2, whereas the numerical settings are listed in Table 3. The 3D spout fluidized bed set-up used by Link et al. (2007) is schematically represented in Fig. 1. The side walls of the bed are made of aluminium, while the 
front and back walls are made of polycarbonate. Pressurized air was fed to the bed through three separate sections. A $2 \mathrm{~mm}$ thick porous plate with an average pore size of $100 \mu \mathrm{m}$ provided a homogeneous gas distribution over the two fluidization sections. Fig. 1 shows that the bed contains a spout section, which is covered by a $0.5 \mathrm{~mm}$ metal gauze and located on the border between the two fluidization sections at the geometrical centre of the bottom plate. The investigations conducted by Link et al. (2007) provide results of the root mean square (RMS) belonging to the flow regimes $B_{1}, B_{2}$ and $B_{3}$ in Table 2 and to particles having properties in Table 1. These results will be compared with the results obtained from the DEM simulations.

Table 1: Particle properties.

\begin{tabular}{|l|c|}
\hline Property & Value \\
\hline Material & Glass \\
\hline$d_{p}$ in $\mathrm{mm}$ & 4.0 \\
\hline$\rho_{p}$ in $\mathrm{kg} / \mathrm{m}^{3}$ & 2526 \\
\hline$e_{n, p \leftrightarrow p}$ & $0.2-0.97$ \\
\hline$e_{n, p \leftrightarrow w}$ & $0.2-0.97$ \\
\hline$e_{t, p \leftrightarrow p}$ & 0.33 \\
\hline$e_{t, p \leftrightarrow w}$ & 0.33 \\
\hline$\mu_{p \leftrightarrow p}$ & 0.10 \\
\hline$\mu_{p \leftrightarrow w}$ & 0.10 \\
\hline
\end{tabular}

Table 2: Flow regimes.

Table 3: Numerical settings.

\begin{tabular}{|l|c|}
\hline \multicolumn{1}{|c|}{ Property } & Value \\
\hline$N_{x} / N_{y} / N_{z}$ & $21 / 14 / 100$ \\
\hline$t_{\text {end }}$ in $\mathrm{s}$ & 8 \\
\hline$N_{p}$ & $4.48 \cdot 10^{4}$ \\
\hline$k_{n}$ in $\mathrm{N} / \mathrm{m}$ & $10^{4}$ \\
\hline
\end{tabular}

\begin{tabular}{|l|l|rr|rr|rr|}
\hline \multirow{2}{*}{ Case } & \multirow{2}{*}{ Flow regime } & \multicolumn{2}{|c|}{$\mathbf{u}_{\mathrm{bg}}$} & \multicolumn{2}{|c|}{$\mathbf{u}_{\mathrm{sp}}$} & \multicolumn{2}{c|}{$\mathbf{u}_{\text {sup }}$} \\
\cline { 3 - 8 } & & {$[\mathrm{m} / \mathrm{s}]$} & {$\left[\mathrm{u}_{\mathrm{mf}}\right]$} & {$[\mathrm{m} / \mathrm{s}]$} & {$\left[\mathrm{u}_{\mathrm{mf}}\right]$} & {$[\mathrm{m} / \mathrm{s}]$} & {$\left[\mathrm{u}_{\mathrm{mf}}\right]$} \\
\hline $\mathrm{B}_{1}$ & Intermediate / & 2.5 & 1.4 & 60 & 34 & 3.7 & 2.1 \\
& Spout-fluidization & & & & & & \\
$\mathrm{B}_{2}$ & Spouting-with-aeration & 2.5 & 1.4 & 90 & 51 & 4.3 & 2.4 \\
$\mathrm{~B}_{3}$ & Jet-in-fluidized-bed & 3.5 & 2.0 & 65 & 37 & 4.8 & 2.7 \\
\hline
\end{tabular}

\section{RESULTS AND DISCUSSION}

First, snapshots of the simulated instantaneous particle positions are presented in Fig. 2, to show the bed behaviour for different restitution coefficients for the three cases. In Fig. 3 the time-averaged bed height averaged over a period of $8 \mathrm{~s}$ is shown. The first $2 \mathrm{~s}$ of the simulations were excluded from the spectral analysis to prevent start-up effects from influencing the results. The simulated results were obtained at a frequency of $250 \mathrm{~Hz}$. It is found that the average bed height decreases with increasing restitution coefficient. This is due to decreasing bubble hold-up. Particles with low restitution coefficient tend to promote the formation of dense regions and passage of gas through the bed mainly in the form of bubbles. It appears that the restitution coefficient influences the bed height most for case $\mathrm{B}_{2}$, the spouting-with-aeration regime. The gas velocity in the spout is quite large in this regime and consequently the particle clusters are dragged higher in the bed. As a result, the bed height increases more with decreasing restitution coefficient in the spouting-with-aeration regime. The amplitude of the fluctuations of the bed height is also shown in Fig. 3 in terms of the root mean square. It can be seen that the RMS for case $\mathrm{B}_{3}$, the jet-in-fluidized-bed regime is much larger than the RMS for the other flow regimes. This is due to the fact that the jet-in-fluidized-bed regime is less stable, caused by the interaction between bubbles and the spout channel. The RMS of the bed height of simulations at $e_{n}=0.97$ is lower for all three flow regime cases. The particles behave more ideal, leading to fewer bubbles in the bed and thus smaller fluctuations in the bed height.

\section{MEASUREMENTS OF GRANULE RESTITUTION COEFFICIENT}

\section{Testing method and material}

Fig. 4 schematically shows the experimental setup that was used for the free-fall experiments presented in this work. Before it is dropped, a granule is being held at a predetermined height $h$ above the target (steel flat wall with thickness of $30 \mathrm{~mm}$ ) with the help of a vacuum nozzle that releases the granule with zero initial velocity and rotation. The granule falls freely onto the target and reaches a rebound height $h_{R}$ after the impact. The movement of the granule close to the contact point is recorded by a high-speed video camera with a frequency of 4.000 frames per second. From the ratio of energies in Eq. (1), it follows that the restitution coefficient is a ratio of relative rebound velocity $v_{R}$ to that before the impact $v$. These velocities were determined from captured impacts using self programmed software on the basis of Matlab. 


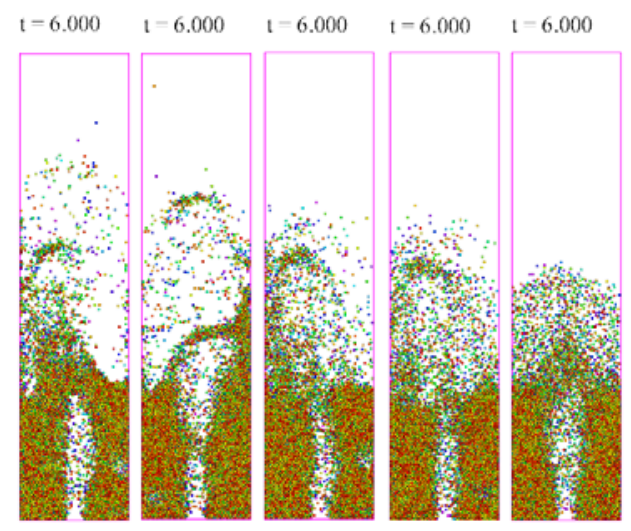

case $B_{1}$

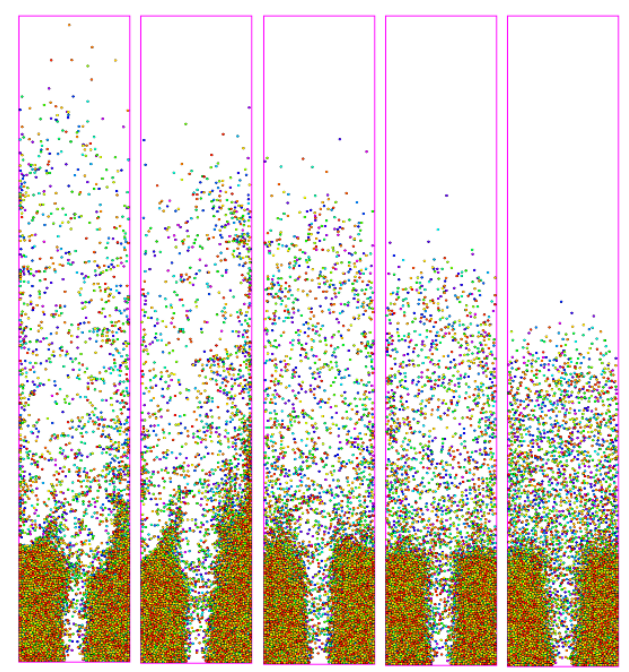

case $B_{2}$

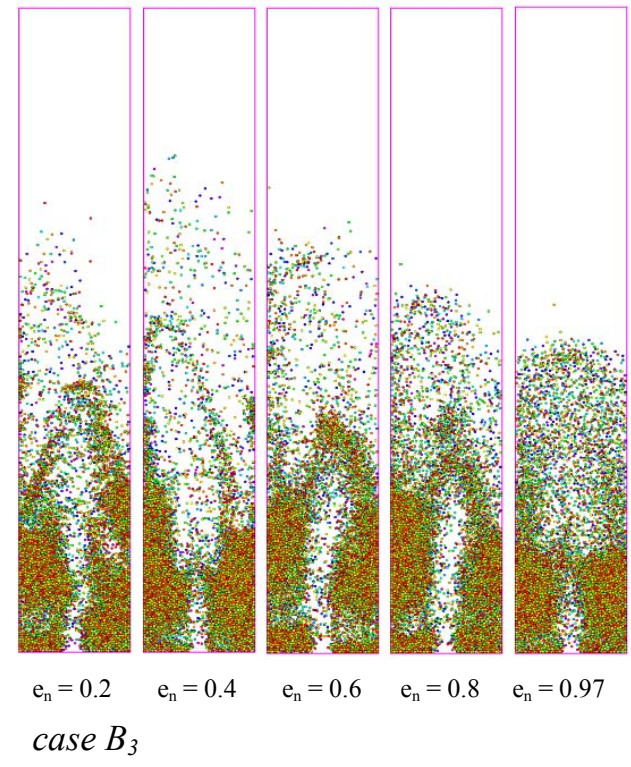

Fig. 2: Snapshots of the simulated instantaneous particle positions for different restitution coefficients for case $B_{1}$ (intermediate/spout fluidization regime), $B_{2}$ (spouting-with-aeration regime) and $B_{3}$ (jet-in-fluidized-bed regime) at simulation time $t=6.0 \mathrm{~s}$.
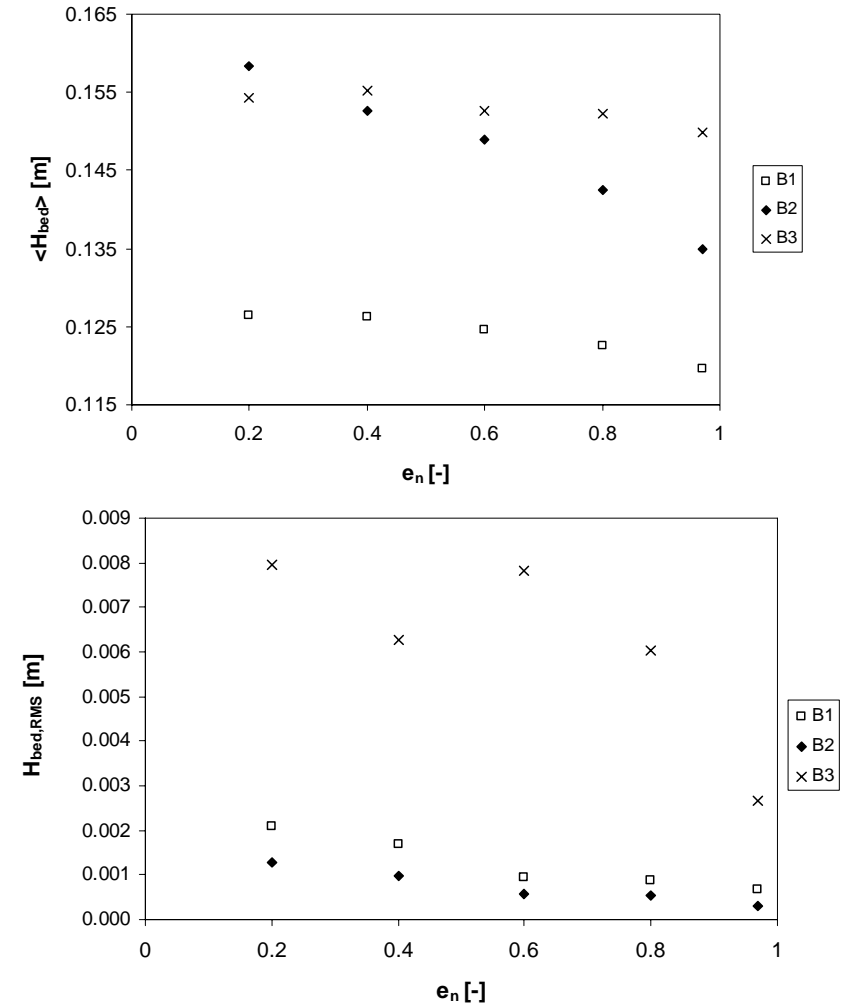

Fig. 3: Time-averaged bed height $H_{\text {bed }}$ (top) and RMS of bed height $H_{\text {bed,RMS }}$ (bottom) for different restitution coefficients $e_{n}$ for case $B_{1}$ (intermediate / spout - fluidization regime), $B_{2}$ (spouting with - aeration regime) and $B_{3}$ (jet-in-fluidized-bed regime).

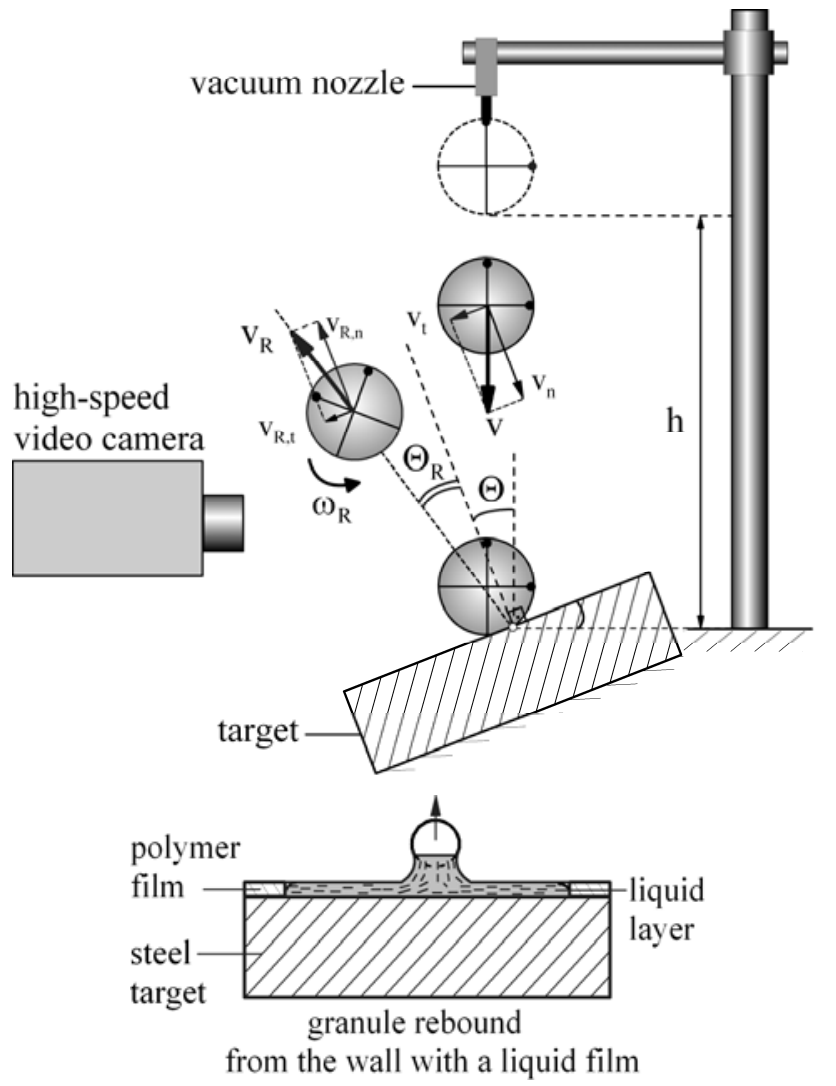

Fig. 4: The experimental setup for measurement of granule impact on a wall and on a liquid film on the wall. 
As a model material for free-fall tests the spherical $\gamma-\mathrm{Al}_{2} \mathrm{O}_{3}$ granules produced by SASOL were used. The nearly spherical $\gamma-\mathrm{Al}_{2} \mathrm{O}_{3}$ granules have a highly porous ceramic structure and are commonly used in the industry as a drying agent. In previous publications (Antonyuk (2006)), we described the measurements of the physical and mechanical properties of $\gamma-\mathrm{Al}_{2} \mathrm{O}_{3}$ granules, which are also given in Table 4.

In order to examine the influence of the impact velocity on the restitution coefficient of granules, the drop height was varied from $12 \mathrm{~mm}$ to $1.5 \mathrm{~m}$, i.e. the impact velocity was in the range of about $0.5-4.5 \mathrm{~m} / \mathrm{s}$. To describe the oblique impact the angle of incidence $\left(\Theta\right.$ in Fig. 4) was varied from $0^{\circ}$ to $80^{\circ}$. Before the testing the granules were marked to obtain the angular velocity $\omega_{R}$ during image processing.

In addition to dry conditions, the restitution coefficient was obtained for the case of the granule impact on a liquid film on the wall (Fig. 4 bottom). Both distilled water and the water solutions of the hydroxypropyl methylcellulose Pharmacoat ${ }^{\circledR} 606$ with different concentrations $(3,6,10$ mass-\%) for variation of viscosity were used. In order to form the borders for the liquid layer with a predefined height, a polymer ring film was attached to the wall surface. Because of evaporation the liquid thickness decreased with time. The momentary thickness of the liquid film was determined from the total weight of the target and the liquid layer. For accurate measuring of the normal restitution coefficient the normal rebound of the granule must be ensured. Because of nonideal spherical shape of examined granules and defects on their surface, some granules after normal impact rebounded oblique with a rotation. However, during experimental data analysis no influence of the rebound angle below $6^{\circ}$ on the mean restitution coefficient was found. We repeated the free-fall test for each material to obtain 50 nearly vertical rebounds (below $6^{\circ}$ ).

Table 4: Characteristics of the examined granules.

\begin{tabular}{|l|l|}
\hline Property & Value \\
\hline chemical composition & $97.9 \% \gamma-\mathrm{Al}_{2} \mathrm{O}_{3}$ \\
\hline granule size in $\mathrm{mm}$ & $1.6-1.9$ \\
\hline sphericity & 0.95 \\
\hline granule density in $\mathrm{kg} / \mathrm{m}^{3}$ & 1040 \\
\hline pore volume in $\%$ & 68 \\
\hline water content in $\mathrm{kg} \mathrm{water} / \mathrm{kg}_{\text {solid }}$ & 0.023 \\
\hline modulus of elasticity in $\mathrm{kN} / \mathrm{mm}^{2}$ & $14.45 \pm 0.31$ \\
\hline yield force in $\mathrm{N}$ & $8.5 \pm 2.0$ \\
\hline $\begin{array}{l}\text { normal stiffness of } \\
\text { elastic deformation in } \mathrm{N} / \mathrm{mm} \\
\text { elastic-plastic deformation in } \\
\mathrm{N} / \mathrm{mm}\end{array}$ & $2120 \pm 330$ \\
\hline
\end{tabular}

$\mathrm{k}_{\mathrm{L}}$ to unload $\mathrm{k}_{\mathrm{U}}$ with $\mathrm{e}=\left(\mathrm{k}_{\mathrm{L}} / \mathrm{k}_{\mathrm{U}}\right)^{1 / 2}$.

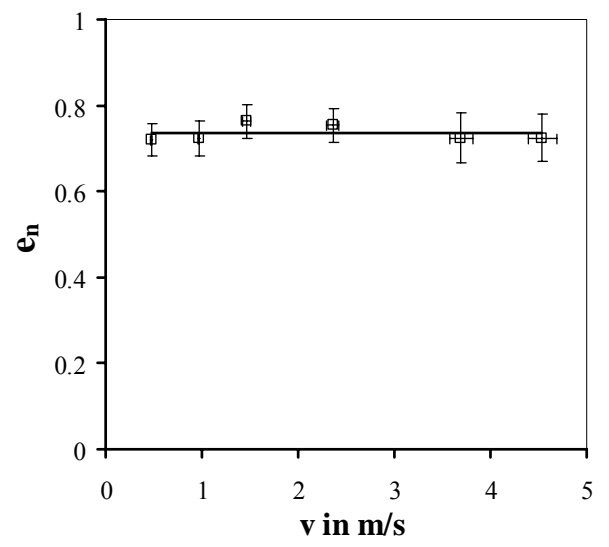

Fig. 5: Normal restitution coefficient of $\gamma-\mathrm{Al}_{2} \mathrm{O}_{3}$ granules versus impact velocity.

\section{Experimental results and discussion}

Fig. 5 shows the normal restitution coefficient of tested granules at different impact velocities. The increase of the impact velocity in examined range does not change the averaged normal coefficient of restitution approximated with a horizontal line in Fig. 5. In other words, the $\gamma-\mathrm{Al}_{2} \mathrm{O}_{3}$ granules show elastic-plastic behaviour $(0<\mathrm{e}<1)$ without viscous deformation during the impact in this velocity range. As revealed by loading-unloading compression tests of $\gamma-\mathrm{Al}_{2} \mathrm{O}_{3}$ granules in Fig. 6, the magnitude of maximum load $\left(\mathrm{U}_{\mathrm{i}}\right)$ does not affect the ratio of energy loss to the elastic strain energy (Antonyuk (2006)). This behaviour describes the model of Walton and Braun (1986) based on linear force-displacement relationships for loading and unloading, when the ratio of energies from Eq. (1) is transformed to the ratio of contact stiffnesses of load

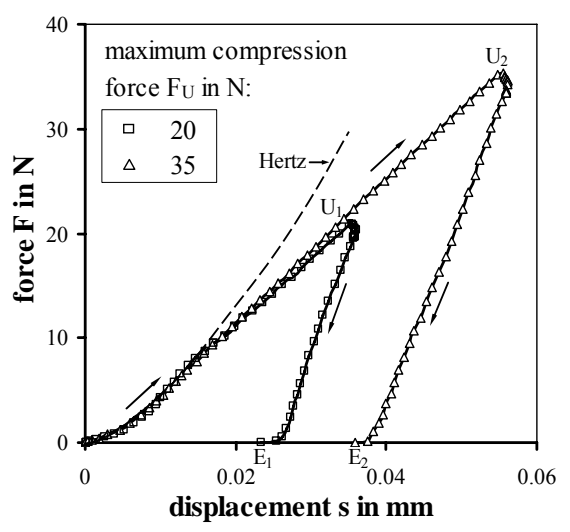

Fig. 6: Typical loading-unloading curves measured by compression tests of $\gamma-\mathrm{Al}_{2} \mathrm{O}_{3}$ at different maximum forces.

Substituting the contact stiffness during elastic loading (Table 4), the stiffness during the unloading is then $\mathrm{k}_{\mathrm{U}}=3368 \mathrm{~N} / \mathrm{mm}$. Under the assumption that the force-displacement behaviour during slow loading is approximately the same as during dynamic stressing, this fact can give a rational explanation for constant restitution coefficient. 
The coefficient of restitution in the normal direction does not depend on the impact angle (Fig. 7 (a)). However, the coefficient of tangential restitution decreases with target inclination and it reaches a minimum at an impact angle close to $30^{\circ}$. By the impact below this angle the granule rolls. At angles higher than about $55^{\circ}$ the coefficient of tangential restitution exceeds the normal coefficient of restitution and reaches a value of 1 at angles above $80^{\circ}$ by glancing incidence. Fig. 7 (b) summarizes the measurements of rebound angles and angular velocities of granules versus the impact angle. When the impact takes place at an angle below $55^{\circ}$, the rebound angle of $\gamma-\mathrm{Al}_{2} \mathrm{O}_{3}$ granules is slightly lower than the impact angle. The dotted line shows an ideal case of rolling at $\Theta=\Theta_{R}$ and the coefficient of friction: $\mu \rightarrow 0$. The angular velocity after rebound increases with increasing the impact angle, reaches a maximum at an angle of about $50^{\circ}$ that shows the transition from rolling to sliding.
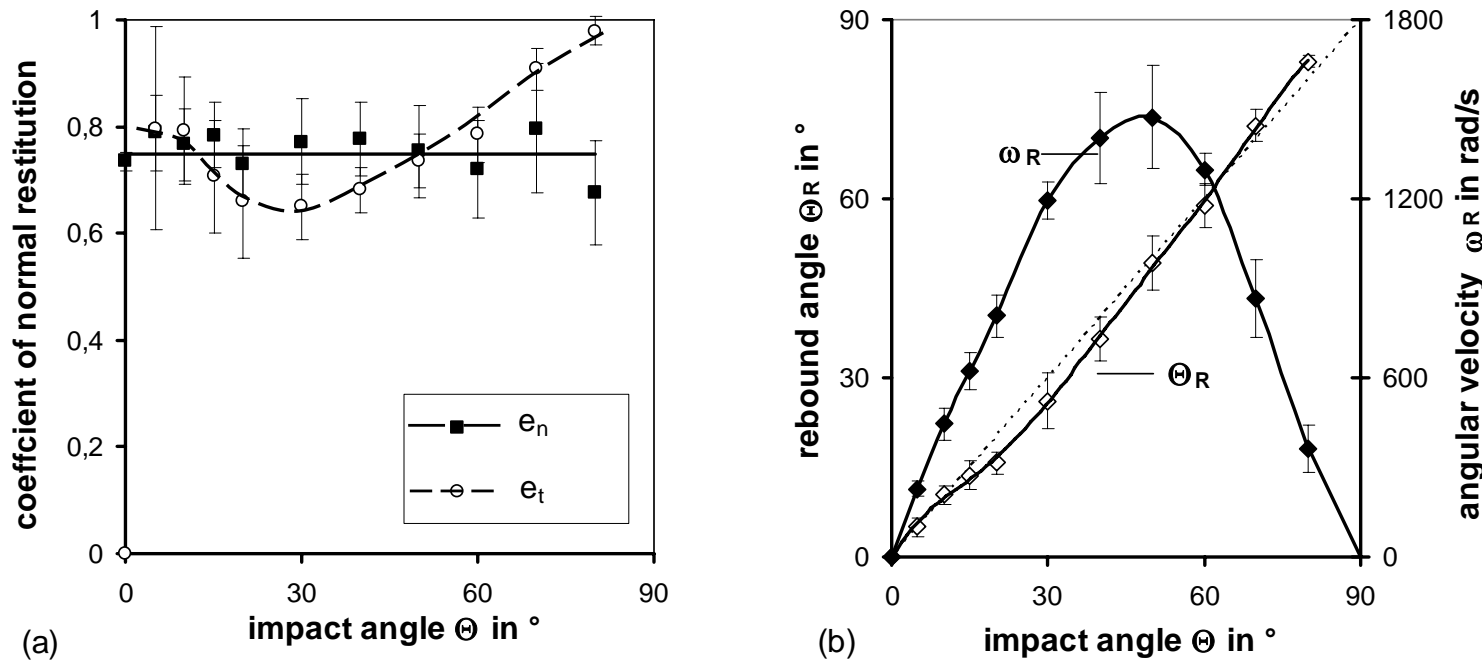

Fig. 7: Effect of the impact angle $\Theta$ on (a) the coefficient of restitution in normal $e_{n}$ and tangential $e_{t}$ direction; (b) the rebound angle $\Theta_{R}$ and the angular velocity $\omega_{R}$ for $\gamma-A_{2} O_{3}$ granules at the impact velocity of $2.3 \mathrm{~m} / \mathrm{s}$.

Fig. 8 shows the rebound of a $\gamma-\mathrm{Al}_{2} \mathrm{O}_{3}$ granule after the oblique impact on a water film. During the rebound, a liquid bridge between the granule and the water film is formed. As the granule moves away from the contact point, the bridge is stretched and finally divided. The residuary liquid phase on the granule surface takes a drop shape that removes the centre of rotation from centre of mass of the particle and thereby changes the rebound trajectory and reduces the angular velocity in comparison to the granule-wall impact without a liquid film. Fig. 9 shows the velocity of granules versus time of incidence and rebound for different viscosities of liquid layer. For the case without the liquid film, the contact between the $\gamma-\mathrm{Al}_{2} \mathrm{O}_{3}$ granule and the wall occurs in a very brief period of time (calculated in the range of 4-7 $\mu \mathrm{s}$, Antonyuk, 2006). Due to additional energy loss during granule-liquid impact and viscoelastic tensile deformation of liquid bridge during the rebound, the contact time, i.e. the time from the beginning of the contact to separation of the granule from liquid in point $\mathrm{S}$ in Fig. 9, increases. Therefore, the restitution coefficient decreases with increasing viscosity and thickness of liquid layer, as the amount of adhesion increases (Fig. 10). Fig 10 shows the thickness $h_{s t}$ of liquid layer at which no rebound occurs, i.e. the granule sticks.

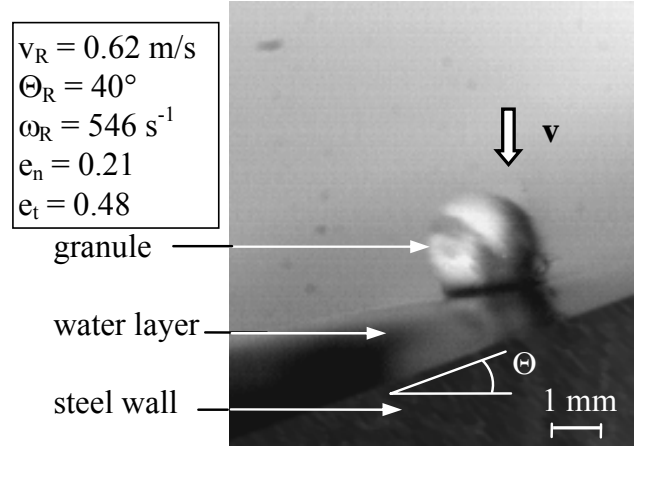

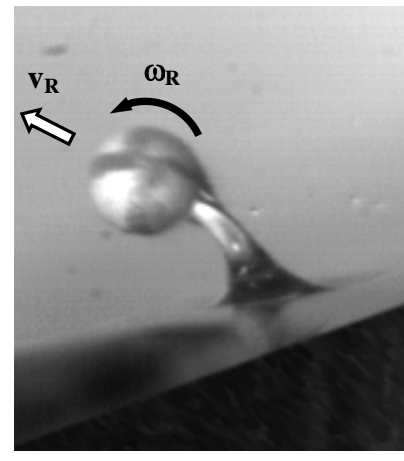

$\mathrm{t}=3.3 \mathrm{~ms}$

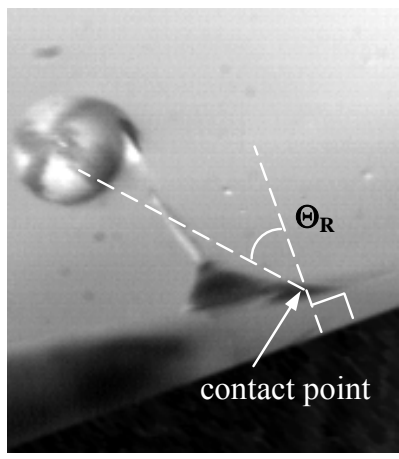

$\mathrm{t}=5.3 \mathrm{~ms}$

Fig. 8: A sequence of frames extracted from a high-speed video recording of $\gamma-\mathrm{Al}_{2} \mathrm{O}_{3}$ granule rebound after impact on the wall with water layer (thickness of the layer of $400 \mu \mathrm{m}$, impact velocity $\mathrm{v}=2.3 \mathrm{~m} / \mathrm{s}$, impact angle $\Theta=20^{\circ}$ ). 


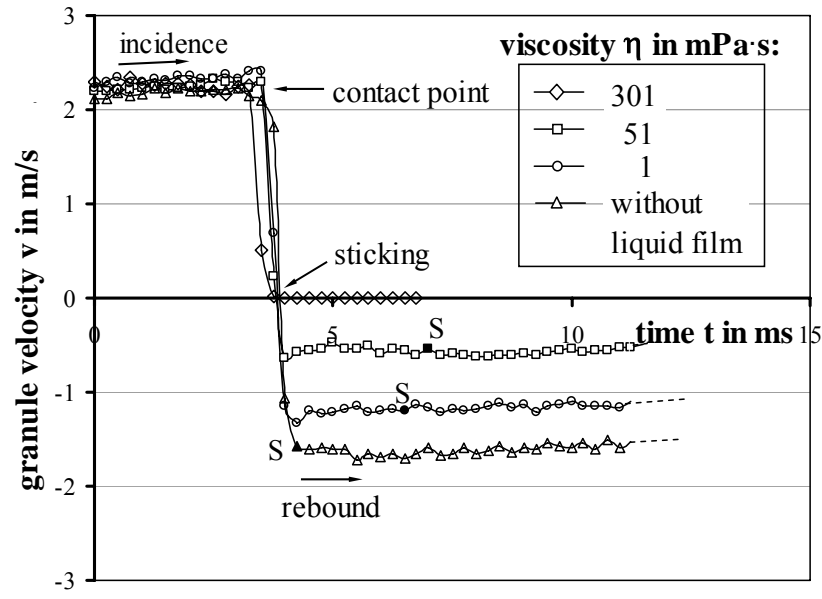

Fig. 9: Typical velocity-time curves during the normal impact and rebound of $\gamma-\mathrm{Al}_{2} \mathrm{O}_{3}$ granule on the liquid layer for different liquid viscosities (layer thickness of $200 \mu \mathrm{m}$ ).

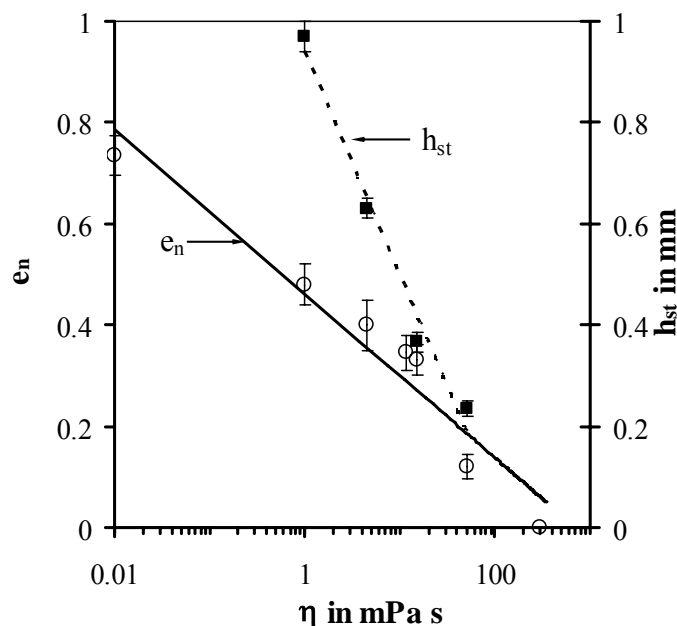

Fig. 10: Effect of liquid viscosity on the normal restitution coefficient $e_{n}$ of $\gamma-\mathrm{Al}_{2} \mathrm{O}_{3}$ granules (layer thickness of $200 \mu \mathrm{m})$ and on the sticking thickness $h_{s t}$.

\section{CONCLUSIONS}

The results of DEM simulations performed in this work show an increase of average bed height with decreasing normal restitution coefficient of particles for investigated flow regime cases in spout fluidized bed. As the restitution coefficient decreases, more bubbles are present causing more pronounced heterogeneity (instability) in the overall flow structure of the bed.

The results of free-fall tests revealed that the $\gamma-\mathrm{Al}_{2} \mathrm{O}_{3}$ granules show elastic-plastic behaviour during the impact, when the coefficient of normal restitution is independent of the impact velocity. Therefore, for the restitution coefficient used in DEM simulations of a fluidized bed with dry granules, where the particle velocity is no higher than $4.5 \mathrm{~m} / \mathrm{s}$, a constant value can safely be assumed. From the study of oblique impact was found that the coefficient of tangential restitution shows a minimum at an angle of about $30^{\circ}$, as the normal restitution coefficient remains constant. For the impact a granule on a liquid film on the wall, the increase of liquid viscosity decreases greatly the restitution coefficient and thickness of liquid layer at which the granule sticks. These results will be used for the selection of an adequate contact model and for its following implementation during modelling of particle dynamics in fluidized bed.

\section{NOTATION}

$\mathrm{d}_{\mathrm{p}} \quad$ diameter, $\mathrm{m}$

$\mathrm{m}_{\mathrm{p}} \quad$ particle mass, $\mathrm{kg}$

$\mathrm{N}_{\mathrm{x}}, \mathrm{N}_{\mathrm{y}}, \mathrm{N}_{\mathrm{z}}$ number of gridcells $\mathrm{x}, \mathrm{y}$ and $\mathrm{z}$-directions,-

$\mathrm{N}_{\mathrm{p}} \quad$ number of particles, -

$\mathrm{t}$ time, $\mathrm{s}$

$\mathrm{u} \quad$ gas velocity, $\mathrm{m} / \mathrm{s}$

$\mathrm{v}, \mathrm{v}_{\mathrm{R}} \quad$ impact and rebound velocities, $\mathrm{m} / \mathrm{s}$

$\eta \quad$ viscosity, $\mathrm{Pa} \cdot \mathrm{s}$ $\theta, \theta_{\mathrm{R}}$ impact and rebound angles, ${ }^{\circ}$

$\mu \quad$ dynamic friction coefficient, -

$\rho_{\mathrm{p}} \quad$ particle density, $\mathrm{kg} / \mathrm{m}^{3}$

bg background fluidization

$\mathrm{p} \leftrightarrow \mathrm{w}$ particle-wall

sp spout fluidization

sup superficial

$\mathrm{mf}$ minimum fluidization

end end of simulation

\section{REFERENCES}

Antonyuk, S., Khanal, M., Tomas, J., Heinrich, S., Mörl, L.: Chem. Eng. and Proc. 45 (2006), pp. 838-856. Antonyuk, S., 2006: Dissertation, Docupoint publisher.

Fu, J., Adams, M., Reynolds, G., Salman, A., Hounslow M.: Powder Technol. 140 (2004), pp. 248-257.

Hoomans, B.P.B., Kuipers, J.A.M., Briels, W.J., van Swaaij, W.P.M.: Chem. Eng. Sci. 51(1996), pp. 99-118.

Kharaz, A.H., Gorham, D.A., Salman, A.D.: Powder Technol. 120 (2001), pp. 281-291.

Kruggel-Emden, H., Simsek, E., Rickelt, S., Wirtz, S., Scherer, V.: Powder Technol. 171(2006), pp. 157173.

Link, J.M., Godlieb, W., Deen, N.G., Kuipers, J.A.M.: Chem. Eng. Sci. 62 (2007), pp. 195-207.

Mörl, L., Heinrich, S., Peglow, M.: Handbook of Powder Technol. 11, Elsevier Sci. (2007), pp. 21-188.

Passos, M.L., Mujumdar, A.S.: Powder Technol. 110 (2000), pp. 222-238.

Vieira, M.G.A., Rocha, S.C.S.: Chem. Eng. and Proc. 43 (2004), pp. 1275-1280.

Walton, O.R., Braun, R.L.: J. Rheol. 30(1986), pp. 949-980. 